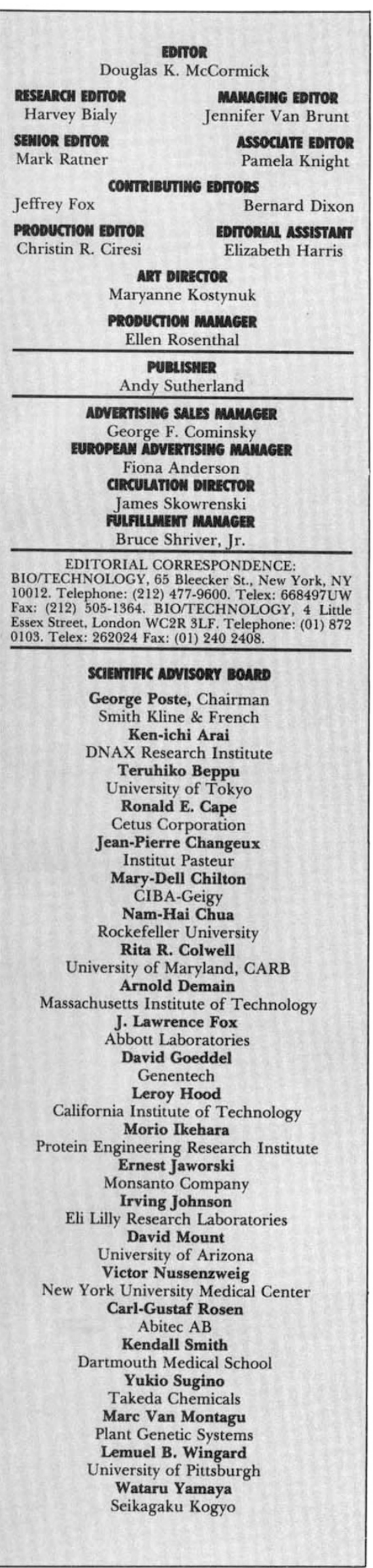

\title{
THE FIRST WORD/ CAVE-IN
}

7 he headline should have read "Supermarket Cave-In Injures Four." Instead, the newspapers trumpeted "Five Food Chains Refuse Milk of Hormone-Treated Cows" (LA Times), "Grocery Chains Refuse 'Engineered' Milk Products" (Washington Post), or "Sour Reception Greets Milk Hormone" (The Wall Street Journal).

At the end of August, when Bio/Technology was already at the printer, five of the largest American food retailing chains (Kroger, Safeway, Pathmark, Stop \& Shop, and Vons, with combined annual sales of over $\$ 48$ billion) announced what amounts to a boycott of milk produced by cows involved in field trials of bovine somatotropin (BST): Using the rhetoric of due caution " The basic rationale is that use of the drug is still experimental," said one retailer spokeswoman), the supermarkets declared that their in-house dairy products would be free of artificial BST. Kraft and Borden, mammoth U.S. milk processors, are also backing off.

In 1987, we remember well, Mr. Rifkin promised the members of the Association of Biotechnology Companies that he would make a test case example of BST, manning the barricades with a host of grassroots supporters at his back.

In fact, the supermarketers are knuckling under not to a groundswell of popular sentiment but to a whisper of a hint of a threat of an anti-bio. tech consumer backlash. All it took, apparently, was a letter. At the beginning of August, the Foundation on Economic Trends circulated a letter to the dozen largest U.S. food-retailing companies. The missive adverted to a paper (as yet unpublished) by Samuel S. Epstein, a pathologist at the University of Illinois Medical Center (Chicago) who writes mostly on carcinogenesis. The paper itself appears to have more holes than a field full of gophers. But, doubtless fearing headlines like "Supermarkets Ignored Warning on Mutant Milk," almost half of the companies Mr. Rifkin contacted backed off.

Atemi waza is the art of applying small pressures to your opponent's vulnerable points - acupressure with a bad temper, if you will. Mr. Rifkin has once again shown us how to practice this most painful of martial arts on the body politic. Once again he has managed his timing to manufac. ture what appears to be-but is not-a victory based on science.

Now, BST belongs to that relatively small class of biotech products for which we have no notable enthusiasm. Aiming a productivity-enhancer at an already flooded market never appealed to our admittedly donnish marketing sense. But whatever its merits, BST deserves a chance to succeed or fail on its own merits. If consumers refuse to buy milk produced with the aid of BST, well, that's life in the big city. If the farmers don't like the economics of BST and refuse to use it, that's the way the game is played.

But blackballing BST on the basis of a single unreviewed paper?

The proper response would be a scientists' counter-boycott of supermarkets that ban BST-derived milk. We tried, however, to institute such a policy at home: It was politely suggested that we might better employ our energies elsewhere than mucking about in the perilously balanced household accounts.

Still, it might pay for those of us with expert knowledge to write the men and women who run these companies, protesting the drum-head condemnation of the industry and suggesting that there might be more to the issue than a single tiny Washington, DC, lobbyist is willing to tell.

Safeway ( $\$ 18.3$ billion annual sales): James A. Rowland, President, Safeway Stores, Fourth \& Jackson Sts., Oakland, CA 94660.

Kroger ( $\$ 17.6$ billion): Joseph A. Pichler, President, The Kroger Co, 1014 Vine St., Cincinnati, OH $45201-1199$.

Pathmark ( $\$ 5.1$ billion): James D. Dougherty, President, Supermarkets General, 200 Milik St., Carteret, NJ 07008.

Stop E Shop ( $\$ 4$ billion): Carol R. Goldberg, President, Stop \& Shop Companies, One Bradlees Circle, Braintree, MA 02184.

Vons ( $\$ 3.2$ billion): Roger E. Strangeland, President, The Vons Com. panies, 10150 Lower Azusa Rd., El Monte, CA 91731-1117. 